\title{
Program Evaluation for Internship/ Residency Programs in Academic and Research Libraries
}

\section{Julie Brewer and Mark D. Winston}

\begin{abstract}
Academic libraries are turning increasingly to internship/residency programs to enhance their recruitment efforts. Yet, little evaluative information is available to measure the effectiveness of these programs or to justify funding for them. This article outlines the necessary components of an evaluation model for internship/residency programs based on a survey of academic library deans/directors and program coordinators. The study identifies the key evaluation factors that library administrators consider most important for measuring internship/residency programs, as well as the frequency, format, and sources of input for effective program evaluation.
\end{abstract}

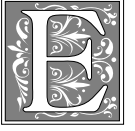

valuating the effectiveness of library programs is a basic part of good management. Administrators need data from such evaluation to guide future decisions regarding the continuation or modification of library programs. In addition, program evaluation criteria often are needed to justify funding for new programs. Unfortunately, measuring program effectiveness is not always given high priority. Administrators often lack adequate information for judging whether library programs are working as planned or how well they are serving organizational objectives. Program data, where they do exist, are often anecdotal, incomplete, and difficult to share with other institutions.

With the number of internship/residency programs in academic libraries increasing in the past decade, the need for effective program evaluation is becoming more and more apparent. Academic library administrators need to understand how such programs affect recruitment and retention goals, organizational productivity and flexibility, the quality of library services, and the career development of program participants. With so little information, administrators interested in starting such programs have difficulty designing them and justifying their cost.

This article provides information related to program evaluation for library administrators interested in enhancing the effectiveness of existing internship/residency programs or in starting new internships/residencies. It reports the results of a research study on internship/residency programs in academic and research libraries in the United States. The primary focus of this research was to identify the necessary components of an evaluation model for such programs. The study outlines key

Julie Brewer is Coordinator of Personnel and Staff Development in the University of Delaware Library; email: jbrewer@udel.edu. Mark D. Winston is an Assistant Professor in the School of Communication, Information and Library Studies, at Rutgers University; e-mail: mwinston@scils.rutgers.edu. 
evaluation criteria and guidelines as identified by current program coordinators and library administrators. Suggestions for both formal and informal feedback measures also are provided.

\section{Background and Review of the Literature}

A review of the library literature reveals few systematic attempts to evaluate internship/residency programs. ${ }^{1}$ The importance of evaluation for such programs is discussed in two publications. The Association for Library and Information Science Education (ALISE) published a set of guidelines for the administration of residency programs, identifying program evaluation as a key component. However, the ALISE guidelines related to program evaluation are very general, recognizing that residencies vary from library to library. The guidelines focus on how explicit, formal evaluative procedures benefit individual residency programs. They suggest that establishing and defining specific programmatic goals is a key part of the evaluation process. Communicating these goals prior to the recruitment and selection process also is important in planning for program evaluation. ${ }^{2}$

\section{The target population of the study included all academic and research libraries known to "host" post- master's internship/residency programs.}

Julie Brewer discussed program evaluation in a 1998 publication titled "Implementing Post-Master's Residency Programs." ${ }^{3}$ In addition to identifying various evaluation methods and criteria, she suggested that each program component-such as the interview process, the seminar series, and placement assistance-be evaluated. Moreover, both direct costs (salary and travel allotments) and indirect costs (staff time, equipment, and supplies) need to be considered.

An ARL survey of residency programs in 1992 identified a number of methods and criteria used for evaluating the suc- cess of residencies in member libraries. ${ }^{4}$ Informal feedback from residents and library staff was the most common method of gathering evaluative information. Examples of criteria used to evaluate the success of internship/residency programs included placement in a full-time professional position following the residency, publication in the library literature, or active involvement on a national committee.

A more recent study of internships/ residencies in ARL member libraries by Teri Switzer and William Gentz identified similar evaluation methods and criteria. ${ }^{5}$ Feedback from interns/residents and successful completion of the program were prime indicators. Switzer and Gentz also suggested longitudinal measures, such as follow-up with former interns/residents and their subsequent employers after several years to understand the programs' long-term value.

The perspectives of past interns/residents are very valuable in evaluating internship/residency programs. Many individual accounts of internship/residency experiences are found in the library literature. ${ }^{6}$ These personal accounts offer valuable insights for library educators, students, and program coordinators. They can assist graduate school advisors and placement officers in informing students about alternative career choices and professional opportunities. Students interested in applying to internship/residency programs can learn what to look for in selecting various types of programs. For library administrators, this type of documentation offers qualitative feedback that may not be captured with more traditional evaluation methods.

The most comprehensive study evaluating internship/residency programs from the perspective of former program participants was conducted in 1994 by ALA's Office for Library Personnel Resources (OLPR). ${ }^{7}$ More than one hundred former interns/residents provided feedback describing and evaluating their internship/residency experiences. The OLPR study summarized qualitative information about various program compo- 
nents. Attributes of effective supervisors, program coordinators, and assignments were identified. The study provided less guidance on how to evaluate the impact of these programs on career progression.

The literature review for this study shows growing interest in internship/ residency programs. Descriptive information about individual programs and personal experiences with them is more available today than ever before. Yet, although library educators and administrators acknowledge the need for program evaluation, there is little evidence of systematic, in-house evaluation processes for internship/residency programs. Only the University of Minnesota has reported on a formal review of its residency program. ${ }^{8}$ The research described in this article identifies the evaluation criteria and guidelines considered most important for library administrators embarking on an internal program evaluation.

\section{Methodology}

To gather data for the study, survey methodology was used, with a direct mailing of questionnaires to the library directors and program coordinators of institutions that have internship and/or residency programs in place. The survey instrument used was developed to measure perceptions regarding the importance of a number of factors in providing a comprehensive evaluation of pre- and post-master's internship and residency programs. It was designed to address issues such as the program's nature and duration, the importance of various factors in its evaluation, and staff participation in and frequency of evaluation.

Because the questionnaire developed for this study had not been used and its validity proven in prior research, a pilot study was undertaken to address the issues of intelligibility, ease of answering, and time needed to complete the survey instrument. A draft was sent to three library directors and two personnel/human resources specialists in a total of five different university libraries that do not have residency/internship programs in place. They were asked to complete the questionnaire and to answer additional questions related to the clarity of the questions posed, the overall level of difficulty involved in completing the instrument, and the amount of time required to complete it. All of the pilot study participants indicated that the survey instrument was "easy" or "very easy" to complete and that the questions posed were "understandable." In addition, they made a number of comments regarding format and how to reword certain questions to make them clearer and to gather further information. Their comments formed the basis for the revisions that led to the final questionnaire that was sent to the survey participants. The pilot study participants indicated that it took less than fifteen minutes to complete the questionnaire.

Participants were asked about the importance of various factors in the evaluation of internship/residency programs, with a specific focus on size, diversity, and quality of the pool of applicants; the work-related performance of the residents/interns; and resident participation in scholarly and service activities. In addition, participants were asked about the importance of resident completion of the program and placement in subsequent positions in the host institution or other academic libraries, the level of involvement of former residents in the current program, and the change in the minority composition of the library staff and the pool of applicants for other positions. Finally, respondents were asked about what members of the library staff should be involved in the evaluation process.

The target population of the study included all academic and research libraries known to "host" post-master's internship/residency programs. Since her participation in the ARL and OLPR studies, Brewer has maintained an informal roster of such programs in the United States, with contact information and program specifics such as duration of the program and name and mailing address of the program coordinator. Much of this information is now available to the public on the 
ARL Research Library Residency \& Internship Programs database on the Internet. ${ }^{9}$

In total, twenty-two institutions were identified, including nineteen college and university libraries, one law library, an archives, and a federal agency. The American Library Directory and the institutional Web sites were used to identify the current directors of these libraries and their mailing addresses. Questionnaires, with cover letters and stamped, self-addressed, return envelopes, were mailed to each of the directors and program coordinators. A follow-up mailing was done, as well. In total, twenty institutions replied, reflecting an overall rate of return of 90.9 percent. One of the respondents noted that the institution has discontinued the residency program and did not complete the questionnaire. As a result, the rate of return of questionnaires that were usable represented nineteen institutions (86.36\%).

Two questionnaires were sent to each institution to allow for responses from the library dean/director and the coordinator of the residency/internship program so as to provide an "understanding (of) multiple administrative needs and perspectives, in the event that your responses vary." Further, participants were informed that "What is most important to us [the researchers] is receiving a response from each institution." Thus, in some cases, one response was provided and in other cases, two. Thirty responses were received, including one questionnaire that was not completed, which gave an individual rate of return of 65.9 percent $(29 / 44)$. The data are described on the basis of the nineteen institutional responses or the twenty-nine individual responses (and usable questionnaires returned), depending on the nature of the issue being addressed.

\section{Characteristics of Programs and Respondents}

Respondents were asked to characterize the internship/residency programs on the basis of duration, focus, and number of years the programs have been in existence. Fifteen of the nineteen programs represented in the study $(78.9 \%)$ were of a duration of more than one year and offered only a post-master's in library and information science (MLS) experience for the residents. Two of the post-MLS-only programs were one year in length but offered the option or opportunity for a second year. Three programs were more than one year in length and included both preand post-MLS components. Only one of the programs was a one-year post-MLSonly program.

In terms of characterizing the recruitment focus of the programs, nearly twothirds $(63.2 \%)$ of the respondents described their programs as focusing on recruiting minority residents, with the other 36.8 percent focusing on "open recruitment." The focus of one of the programs was changing to open recruitment after having focused on minority recruitment for a number of years. And one of the programs was described as involving "open recruitment with a focus on minority recruiting."

While nearly half $(47.4 \%)$ of the programs had been in operation for four years or less, nearly three-quarters $(73.7 \%)$ had been in place for ten years or less. On average, the programs had been in existence for approximately nine years. One program had been in place for forty years and a number of others for between ten and eighteen years.

In terms of those who completed the questionnaires, almost 25 percent were deans or directors, 27.6 percent each were either assistant deans/directors or human resources/personnel directors, and 17.2 percent were internship/residency program coordinators. ${ }^{10}$

\section{Findings and Discussion}

Library administrators and program coordinators were asked to indicate the importance of a number of factors related to their evaluation of the programs in their institutions. In addition, they were asked about the importance of input from library staff members involved with the programs, about the importance of a written evaluation or assessment, and how often programs should be evaluated. 
TABLE 1

Factors Considered in Program Evaluation

\begin{tabular}{lr} 
Evaluation Factor & $\begin{array}{r}\text { \% Indicati } \\
\text { "Very Importa } \\
\text { "Somewhat Imp }\end{array}$ \\
\hline Placement in other academic libraries & $100.0 \%$ \\
Quality of applicant pool & $96.6 \%$ \\
Completion of program by residents & $93.1 \%$ \\
Work performance of residents & $89.7 \%$ \\
Diversity among applicant pool & $89.7 \%$ \\
Participation of department heads in development of & \\
resident assignments & $89.6 \%$ \\
Change in minority representation & $86.2 \%$ \\
Extent to which program supports library's diversity plan & $86.2 \%$ \\
Former residents' involvement in refining the program & $82.8 \%$ \\
Continuation of second year, if applicable & $75.8 \%$ \\
Resident's committee activities & $72.4 \%$ \\
Placement in host institution & $62.1 \%$ \\
Resident's research activities & $62.0 \%$ \\
Size of applicant pool for the program & $58.6 \%$ \\
Former residents' assistance with recruitment & $55.2 \%$ \\
Program coordinator's contact with former residents & $55.1 \%$
\end{tabular}

\section{Evaluation Factors}

The evaluation factors to be considered by the study participants related to the nature of the pool of applicants for the programs, the job performance and other activities of the residents, placement, and so on. Table 1 lists the evaluation factors considered in this study in order of importance.

The fact that 100 percent of the respondents indicated that a very important or somewhat important measure of their program is the placement of residents in permanent professional positions in academic libraries indicates a clear commitment to the recruitment of new librarians. Preparing new librarians for continuing successful careers in academic librarianship seemed to be a primary objective of all the internship/residency programs represented in this study. Although former interns/residents may excel in nonacademic library careers after completing their program, this would not be considered successful placement in terms of program objectives. A much smaller percentage of the respondents $(26.7 \%)$ indicated that intern/resident placement in the host insti- tution after completion of the program was a very important measure of the program. Thus, internship/residency programs appear to support the overall professional interest of attracting new graduates to academic libraries.

Other factors that appear to be most important for program evaluation relate to quality of the applicant pool, completion of the program by the residents, and work performance. The factor that was identified as "very important" by the largest percentage, or nearly 90 percent of the respondents, was that of quality of the pool of applicants for the program. Attracting the highest-qualified graduates reflects positively on internship/residency programs. Resident/intern completion of the program was rated as "very important" by 72.4 percent of the respondents and "somewhat important" by 20.7 percent. With regard to resident work performance, as evaluated by supervisors, more than twothirds of the respondents viewed this factor as very important and an additional 20.7 percent believed it to be somewhat important. 
Diversity-related factors ranked high among the respondents' concerns. More than three-quarters noted that ethnic diversity among the pool of applicants was very important. An additional 13.8 percent identified diversity among the applicant pool as being "somewhat important," with slightly more than 10 percent not responding or noting that it was not important at all. Change in minority representation on the library staff also was noted as very important by nearly twothirds of the respondents. In addition, more than half indicated the extent to which the program supports the library's diversity plan as very important.

\section{Specifically, all the deans/directors noted that the continuation of the residents for a second year was very important...}

As might be expected, in a number of instances the nature of program recruitment (i.e., focusing on the recruitment of minority interns/residents in contrast to open recruitment) was associated with significant differences in terms of the importance associated with program evaluation factors. Change in minority representation on the library staff was very important to 75 percent of the study participants associated with minority residency programs, with the remaining 25 percent noting that change in minority representation was somewhat important. All the respondents who indicated that this factor was not important at all or was of minimal importance or who indicated neutrality had programs that focus on open recruitment. However, 44.4 percent of the respondents with programs that did not focus specifically on minority residents indicated that change in minority representation was very important. The extent of the difference in responses was represented by a chi-square value of 0.035 .

Similarly, the extent to which the program supports the library's diversity plan was identified as being very important by fourteen of the nineteen respondents with minority intern/residency programs and as somewhat important by the remainder of those with such programs. Again, all the study participants who noted that this evaluation factor was either not important or of minimal importance had programs that did not focus on minority residents. However, 66.7 percent of those with open-recruitment programs indicated that supporting the diversity plan was somewhat or very important. The associated chi-square representing the level of difference on the basis of type of program and importance of the evaluation factor was 0.020 .

In relation to the importance of ethnic diversity within the applicant pool, 85 percent of those with minority internship/resident programs said this factor was very important, with the remaining 15 percent categorizing it as somewhat important. As represented by a difference that was approaching significance (0.099), slightly more than half $(55.6 \%)$ of those respondents with open-recruitment programs viewed diversity among the pool of applicants as a very important evaluation factor and 22 percent each identified it as somewhat important or not important at all.

The nature of the program also was associated with a difference in terms of the importance of placement of residents in permanent professional positions in the host institution. As represented by a chisquare of $0.105,75$ percent of the respondents with internship/residency programs that focused on minority recruitment indicated that professional placement in the host institution was very important (30\%) or somewhat important (45\%). However, 33.3 percent of the study participants with open-recruitment programs described professional placement of the residents in the host institution as not important at all, with 22.2 percent of this group noting that it was of minimal importance.

In the case of the minority internship/ residency programs, 57.9 percent of the respondents said that the level of involvement of former residents in refining the program was very important, as compared with slightly more than 10 percent of those 
with open-recruitment programs, as represented by a chi-square of 0.087 . However, 77.9 percent of the respondents with openrecruitment programs noted that former resident involvement with refining the program was somewhat important.

In terms of the importance attached to the program evaluation factors, there was some distinction on the basis of the job title of the person completing the questionnaire. Specifically, in relation to the level of involvement of former residents in assisting with recruitment, the human resources/personnel directors' responses differed from those of the other respondents to a significant degree, as represented by a chi-square of 0.017 . This evaluation factor was identified as very important by six of the eight human resources/personnel directors, whereas none of the deans/directors, assistant deans/directors, or program coordinators identified it as very important. It was described as not important at all by one dean/director, of minimal importance by one assistant dean/director; and nine respondents, representing all of the positions with the exception of human resources/personnel directors, indicated neutrality with regard to its importance.

In terms of the importance of residents continuing in the program for a second year (where applicable), there was a difference that was approaching significance (i.e., a chi-square of $0.07>0.05$ ) in relation to the level of importance as identified by the deans/directors in comparison with their colleagues in other positions in the organization and in relation to the program. Specifically, all the deans/directors noted that the continuation of the residents for a second year was very important, whereas two of eight assistant deans, one of four program coordinators, and two of eight human resources/personnel directors did not provide a response. In addition, three of eight assistant deans / directors and half the program coordinators noted that this evaluation factor was somewhat important.

Generally, respondents with programs that were designed for more than one year and were post-MLS-only programs indicated that program completion by the residents was a very important factor to a greater extent than did respondents with other types of programs, as represented by a chi-square of 0.000 . This distinction was likely based on the potential challenges associated with the participants' completion of this type of program, in comparison to a one-year post-MLS program or a program that involves preand post-MLS components.

Factors such as resident involvement in research/scholarly activities and committee activities, size of applicant pool, involvement of former residents in refining the program, and so on were not identified as being of primary importance. However, these factors were identified as at least s somewhat important by a large percentage of the respondents.

Respondents also were asked to identify other factors, not already addressed by the survey instrument, they considered important in terms of program evaluation. Other factors they suggested included: quality of the experience for the intern/resident, quality and appropriateness of assignments available, "overall acceptance of the program by the staff at large," as well as "growth in acceptance of diversity in staff and cultural awareness on [the] part of staff of [the] library," "recurring funding of the program," "visibility of the program within the university community [in] further establish(ing) librarianship as a professional academic discipline to others in the university community," "reputation" of the program via former residents, resident growth in terms of understanding academic libraries and personal confidence and ability, effectiveness of the mentoring provided, and retention of minority librarians in the profession after initial placement.

\section{Sources of Input}

In terms of the individuals whose input might be important in program evaluation, more than 96 percent of the respondents indicated that the input of residents, supervisors, and deans/directors was 
very or somewhat important (table 2), with input from residents apparently having the most weight. Their input was thought to be very important by almost $90 \%$ of respondents. Whereas the smallest percentage (55.2\%) identified input from mentors as very important, more than 80 percent noted that input from the mentors is at least somewhat important, as was the case in terms of the importance of the input of program coordinators.

In addition, all the respondents with more than one-year pre- and post-MLS programs and two-thirds of those with post-MLS programs intended for more than one year said that input from supervisors was very important. A third of those with more than one-year post-MLS programs indicated that input from supervisors in program evaluation was somewhat important.

The importance of input from mentors in program evaluation appeared to reflect that mentors were more a part of the minority resident programs. In fact, onethird of the individuals with open-recruitment programs indicated "no response" to this survey item, whereas none of those with minority internship/residency programs did so, as represented by a chisquare of 0.022 .

\section{Frequency and Type of Evaluation}

It is interesting to note the respondents' perceptions regarding the frequency of program evaluation. Nearly half $(48.3 \%)$ identified annual evaluation cycles as appropriate for internship/residency programs. An additional 24.1 percent noted less-frequent biennial evaluations as the ideal. Far fewer recommended quarterly, semiannual, or some other evaluation cycle. "Ongoing" evaluation or "continuous feedback" also was considered important. Some respondents identified distinctions with regard to frequent, "informal" evaluation, as compared with more "formal" program evaluations that should be periodic, but less frequent.

Respondents were asked about the importance of written evaluation/assessment of the programs. Whereas 21 percent of those who responded to this survey item indicated that written evaluation is very important, half described it as being only somewhat important. In fact, 17.2 percent were neutral in terms of this factor and the remaining individuals noted that it was of minimal importance or not important at all.

\section{Summary and Conclusion}

Because internship/residency programs exist to enhance recruitment and provide entry-level professional opportunities in academic and research library settings, often with a particular focus on minority recruitment, evaluating the extent to which the programs are successful in accomplishing these ends is an important consideration. This study identified several evaluation factors that library administrators consider most important for measuring residency programs, such as quality of the applicant pool, completion of the residency program, and subsequent placement in an academic library. These factors will be useful in designing program evaluations for internship/residency programs.

The study also identified what library staff should participate in program evaluations. Participants considered input from residents, supervisors, and deans/directors as most important. Input from program coordinators and mentors was viewed as less important in program evaluation. Interestingly, participants associated with programs focusing on the 
recruitment of minority interns/residents value input from mentors significantly more than do participants associated with open-recruitment internship/residency programs.

Study participants recommended that program evaluations be conducted annually or biennially. The responses suggest that formal program evaluation be documented in writing at intervals relative to the intended length of the program. Yet, respondents cautioned that formal, written evaluations should not take the place of more frequent, informal feedback gathered from residents, supervisors, and others involved in the residency program.

The evaluation criteria and guidelines identified in this study offer a model for assessing internship/residency programs in the future. Although concerns about cost (primarily in terms of staff time), the daily pressure of addressing immediate program demands, and in many cases the small size and newness of the program may hinder extensive evaluation methodologies, implementing an evaluation component does not need to be an elaborate process. Documenting select criteria at regular intervals, along with continuing informal feedback, can provide valuable program data.

Understanding and documenting how effectively internships/residencies achieve programmatic goals is essential for planning. Library administrators need information related to program successes and shortcomings to plan more effectively and to justify continued funding. In addition, they will be more persuasive in seeking new funding for internships/residencies when they are able to demonstrate a systematic process for program evaluation.

\section{Notes}

1. In most, though not all, instances, the term intern refers to the pre-MLS component of the program and the term residency to the post-MLS component.

2. "Guidelines for Practices and Principles in the Design, Operation, and Evaluation of PostMaster's Residency Programs," Library Personnel News 10 (May/June 1996): 1-3.

3. Julie Brewer, "Implementing Post-Master's Residency Programs," Leading Ideas 4 (Sept. 1998): 2-7.

4. Internship, Residency, and Fellowship Programs in ARL Libraries, SPEC Kit \#188 (Washington, D.C.: ARL, 1992).

5. Teri Switzer and William Gentz, "Increasing Diversity: Programs and Internships in ARL Libraries," in Advances in Librarianship, ed. Frederick C. Lynden and Elizabeth A. Chapman (New York: Academic Pr., 2000), 169-88.

6. For example, see Jon E. Cawthorne and Teri B. Weil, "Internships/Residencies: Exploring the Possibilities for the Future," in In Our Own Voices: The Changing Face of Librarianship, ed. Teresa Y. Neely and Khafre K. Abif (Lanham, Md.: Scarecrow, 1996): 45-71; Jose Diaz and Kristina Starkus, "Increasing Minority Representation in Academic Libraries: The Minority Librarian Intern Program at the Ohio State University," CERL 55 (Jan. 1994): 41-46; Deborah Hollis, "On the Ambiguous Side: Experiences in a Predominantly White and Female Profession," in In Our Own Voices: The Changing Face of Librarianship, ed. Teresa Y. Neely and Khafre K. Abif (Lanham, Md.: Scarecrow, 1996): 139-54; Joseph A. Boisse and Connie V. Dowell, "Increasing Minority Librarians in Academic Research Libraries," Library Journal 112 (Apr. 1987): 52-54; Betty Glass, "A Time of Transition," Library Journal 111 (Feb. 1986): 127-28; Sarah Shoemaker, "A Unique Experience," Library Journal 111 (Feb. 1986): 125-26; Molly Mahony, "Preparation for the Future," Library Journal 111 (Feb. 1986): 129-30.

7. Julie Brewer, "Post-Master's Residency Programs: Enhancing the Development of New Professionals and Minority Recruitment in Academic and Research Libraries," College E Research Libraries 58 (Nov. 1997): 528-37.

8. Marilyn H. McClaskey, Obianuju Mollel, and Linda DeBeau-Melting, "Making a Good Thing Better: The Residency Program at the University of Minnesota Libraries," presented at the Diversity Now Conference sponsored by The Big 12 Plus Libraries Consortium and the University of Texas at Austin, Apr. 4, 2000.

9. See http://www.arl.org/careers/residencies.html.

10. It should be noted that in some instances the one institutional response is based on collaboration and completion of the questionnaire by the dean/director, the program coordinator, and/or others, as reported informally to the researchers. 